\title{
Ahamkara: A study on the Indian model of self and identity Kriti Gupta and Jyotsna Agrawal*
}

Department of Humanities and Social Sciences, Indian Institute of Technology, Patna, Bihar, India

*Department of Clinical Psychology, National Institute of Mental Health Neurosciences, Bangalore, India

Kriti Gupta, (Lead Author), Research Scholar, Department of Humanities and Social Sciences, Indian Institute of Technology, Patna, Bihar-800013; email: kriti.phs13@iitp.ac.in, Research interests: Positive Psychology, Indigenous Psychology, Indian Psychology, culture, mental health, psychotherapy.

*Dr. Jyotsna Agrawal (Corresponding Author), Assistant Professor, Department of Clinical Psychology, National Institute of Mental Health Neurosciences, Bangalore-56002; email: jyotsnaonline@gmail.com, Research interests: Psychotherapy, Positive Psychology, positive emotions, public mental health, child \& adolescent mental health, culture, Indigenous Psychology, Indian Psychology, Yoga \& Consciousness studies, mind-body medicine, firstperson/ subjective research methodologies.

Acknowledgement: The authors wish to thank Prof. Michael F. Mascolo for his contribution in developing model of mind as per the Indian tradition. We also wish to thank Dr. Smriti Singh for her departmental support. The study was funded under PhD fellowship from IIT Patna, India. 


\begin{abstract}
Ideas around self and identity are at the core of various reflective traditions in both East and West. In the psychological literature, they have multiple meanings. However, they usually reflect the idea of self-sameness across changing time. The current study aimed to explore various ways in which contemporary Indians define their 'self' and if there were any parallel between modern and traditional construal of self. An open-ended Twenty Statements Test (TST) was used along with a quantitative measure Ahamkara Questionnaire (AQ) based on an Indian model of self, known as 'ahamkara'. A sample of 240 educated, adults (Females=104, Males=136; Mean age= 38.17 years, $\mathrm{SD}=11.45$ years; range $20-60$ years) were purposively selected from an urban area of North India and recruited in this mixed-method, cross-sectional research study. Thematic analysis of TST responses uncovered five broad thematic categories in self-concepts: Individuality, Belongingness, Separation, Agency and Spiritual/Transpersonal. Four of them overlapped with sub-components of 'ahamkara'. They also differed with age where Spiritual/Transpersonal theme was frequent in self-concepts of older samples. Quantitative results from AQ also indicated that the level of ahamkara significantly differed with age and gender. These findings have implications for mental health and developing interventions utilising Indian conception of self.
\end{abstract}

Key words: Ahamkara, self, identity, ego, personal meanings, Indian Yogic tradition

\title{
Introduction
}

It has been argued that a general universal psychology ignores the diversity within the world, while studying the human mind and behaviour (Misra and Mohanty 2002; Heppner 2006). Indigenous psychology is one of the emerging approaches, where people and their experiences are understood without de-contextualizing them. It explores human nature within a cultural 
context and provides those principles and solutions which are applicable to the local settings (Salagame 2008). Further, it is appreciated that insights emerging from a non-western context may go beyond applications in similar indigenous settings and have pan-cultural applications, for example, mindfulness and related concepts. Building upon this larger view, a psychological movement based on Indian knowledge tradition, termed as Indian psychology has emerged. It proposes a comprehensive view of human nature, which not only includes the socio-cultural milieu, but also incorporates the spiritual aspect of the mundane existence (Paranjpe 2002; Dalal and Misra 2010). Within the classical Indian tradition also there are a variety of schools, such as Yoga, Vedanta, Jainism and Buddhism with many shared ideas and few where these schools differ vastly. One idea that has got much attention in these traditions is the idea of self, which has been associated with well-being and spiritual growth within the Indian context (Mishra 2010; Misra and Paranjpe 2012; Salagame 2013) and may have global implications too. In the current research, an Indian psychological framework, which is rooted in the ancient Indian scriptures of Yoga and Vedanta schools (Salagame 2008), has been followed. The original Sanskrit terms have been given for significant concepts along with the English translations. These translations are useful, but sometimes they may not fully capture the deeper meanings of many Sanskrit terms (Banth and Talwar 2012).

\section{Ideas on self and ego}

The fundamental question, 'who am I?' has engaged philosophers and enlightened beings (yogis) across centuries, and different terms and concepts have been used to describe the resulting answers. In modern psychology, the conceptualisation of self has also changed over the decades. It has progressed from understanding 'I' as the ego that develops me or my 'self' by separating objects from 'non-self' (James 1890/1950, cited in Bauer and Wayment 2008, p. 9), to 
conceptualising self as a complex memory structure containing one's experiences and knowledge gained across events (Burnkrant and Unnava 1995). Furthermore, many modern psychologists regard ego and self as the same concept, spread across affective (e.g., self-esteem), motivational (e.g., self-enhancement) or psychosocial (e.g., self versus others) dimensions (Leary 2007; Bauer and Wayment 2008). The latter approach has been followed in this article.

\section{Self and ego in Indian tradition}

In the Indian psychological tradition, mediators and yogis have conducted first-person experiential investigations and have provided a range of insights and explanations related to human nature (Salagame 2013). Some of these ideas and concepts appear to not fit completely into the categories of modern psychology and the concept of ahamkara is one of them. The term ahamkara is rooted in Sanskrit language (aham + kara or self + doer) and generally translated as 'ego' in English. Ahamkaral ego in both Yoga and Vedanta tradition of Indian psychology is considered to be the surface self, primarily based on body and phenomenal experiences, and different from a deeper, metaphysical self (Atman or Purusha) (Salagame and Raj 1999; Desai and Collins 1986; Salagame et al. 2005; Jakubczak 2013). It represents an aspect of the mind, which personalises every experience and ascribes everything to oneself; thus, constituting cognitions and feelings of 'me' and 'mine' (Jakubczak 2013; Salagame 2011; Gaur 2011; Reddy 2014). When self-sense gets linked with experience, there is a dominance of self-relevant beliefs, mental images and feelings all over the consciousness, thereby distorting one's perception (Mills 2011) which may even induce arrogance and exaggerated self-appreciation (Gaur 2011). Given such a description, one may consider that ahamkara serves as a broad concept, subsuming both self and identity as defined in modern psychological literature (Salagame 2011). 
While functioning together with the experiencing aspect of mind (manas), organs of perception (jnanendriya) and organs of action (karmendriya), the ahamkara leads to a variety of experiences, ranging from suffering to enjoyment (Salagame et al. 2005; Rao and Paranjpe 2016).

Following diagram represents the integrated Indian model of the mind, which includes ahamkara (Figure 1).

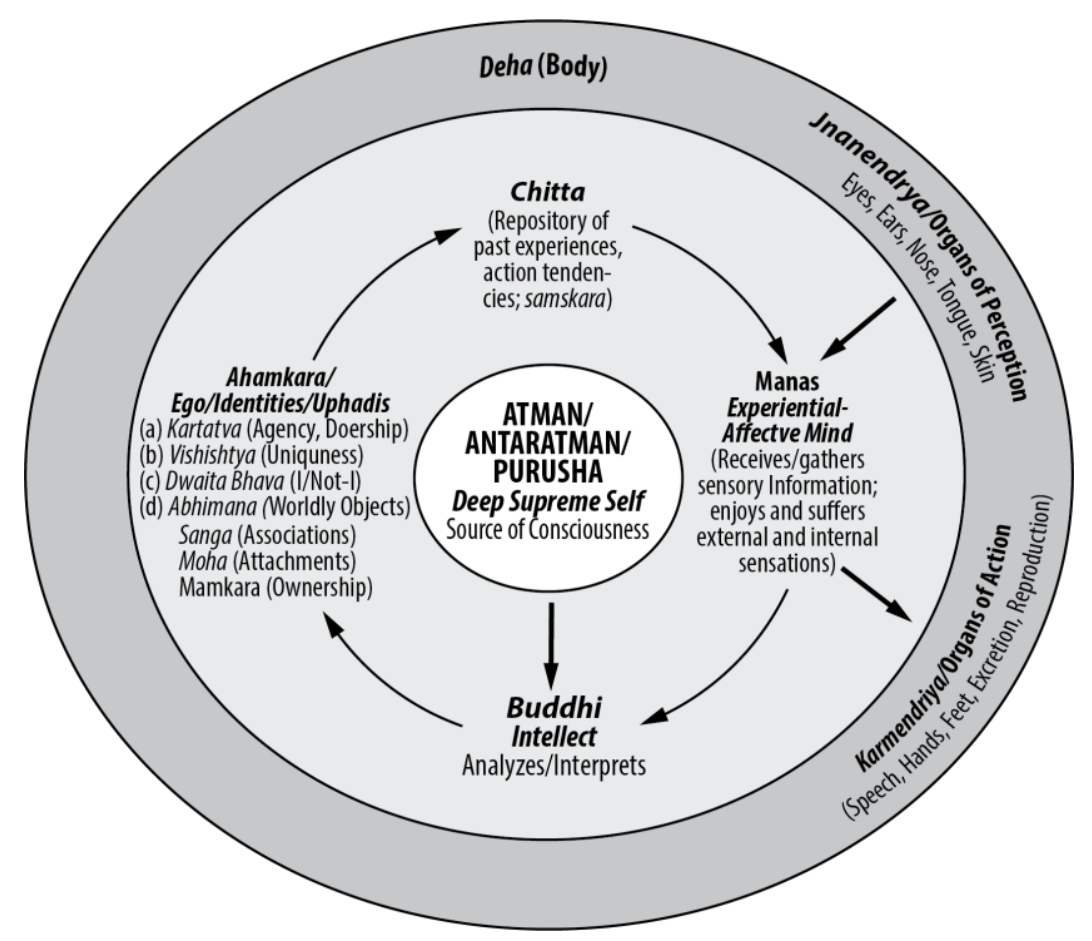

Figure 1: Model of mind as per the Indian tradition ${ }^{1}$

\section{Components of ahamkara/ ego}

Four sub-concepts of ahamkara based on Indian tradition have been described: individuality (vaishishtya), separation-differentiation (dvaita bhava), agency (kartatva) and identification (abhimana). While 'individuality' represents uniqueness, 'separation-differentiation' marks the

\footnotetext{
${ }^{1}$ (Note: In this figure, Chitta has been depicted separately for more clarity about its function, although it is considered to be a part of manas)
} 
feeling of being different from others, 'agency' signifies the sense of doer-ship and 'identification' indicates relationship with worldly objects, involving associations and companionship (sanga), attractions and attachments (moha) and mineness or ownership (mamkara) (Salagame et al. 2005, p. 75). It has further been suggested that people may have multiple identities emerging from these aspects of ahamkara (Gaur 2011). For example, with the sense of doer-ship and association, a person may have the identities of being an executive in an organisation and being a mother. In addition to providing different self-views, each of these identities may enhance each other through interactions and consequently may increase the overall sense of ahamkara.

\section{Ahamkara/ ego and personal growth}

In modern psychology, building a stronger ego has been recommended for developing a high sense of self-esteem (Rao 2014); however, boosting self-esteem has also been found to be associated with narcissism (Baumeister et al. 2003, p.38). Subsequently, there has been an emphasis on 'compassionate and regulated ego', which is interdependent, less self-focused and promotes the growth of self and others (Wayment, Wiist, Sullivan and Warren 2011).

While some Indian traditions (such as Advaita Vedanta) have emphasised complete dissolution of ahamkara, other viewpoints like Sri Aurobindo's 'Integral Yoga' pointed out its utility in terms of formalising each existence and individuating a person from the common mass of humanity (Reddy 1990, p. 80). A disciplined ahamkara may lead to a well-adjusted life, by helping in executing life-sustaining activities, knowing one's roles and responsibilities in the society and engaging with them (Raguram 2007). Empirical studies have pointed out that lower level of ahamkara is associated with lesser anxiety, better functioning (Rekha 1995; Salagame and Raj 1999), harmonious interpersonal relationships (Chang et al. 2014) and a tendency to work 
towards social welfare (Gaur 2011). Therefore for inner growth, one may aim for decreasing or even dissolving ahamkara so as to experience the ultimate happiness embedded in selftranscendence (Mishra 2010; Salagame 2013) as suggested by classical Indian traditions (Salagame 2013; Reddy 2014; Chandur and Sriram 2018). As Sri Aurobindo (1940/2005, p.239) suggested that when an ego-based living is transcended and the inner 'true self' is uncovered, a deeper individuality may be reflected (known as 'psychic being' or Caitya Purusha). Furthermore, meditation is considered to be a common method of lowering ahamkara with empirical support provided by few studies (Raj 1993; Parimala 2001).

It was noted that current empirical research in this area has predominantly used a Western framework for understanding self, even in an Indian sample (Driver 1969; Dhawan et al. 1995; Dolichan 2007) and often used a quantitative research approach (Raj 1993; Rekha 1995; Salagame and Raj 1999; Gaur 2011; Chang et al. 2014). Further, previous researches have also suggested that people vary in their levels of ahamkara (Raj 1993; Rekha 1995; Salagame and Raj 1999; Parimala 2001). Therefore, the current study aimed to explore the various ways in which contemporary urban Indian adults define themselves and if there are any parallel between modern and traditional (especially Vedantic) construal of self. Additionally, ahamkara scores were obtained to investigate any age and gender- based differences in ahamkara levels within the study sample. It may be noted that the classical Indian discourses regard ahamkara as an impediment in the journey of self-realisation, but for a common person ahamkara represents a way to relate with the world (Salagame et al. 2005).

\section{Methodology}

The study had an underlying realist paradigm, where objectivity was brought in by being attentive to the research process, data collection in a naturalistic setting and triangulation of 
research methods. Both the researcher and supervisor had roots in a similar socio-culture background. However, there were also limits in terms of theoretical sampling, reflexivity etc. More details of the methodology are described below.

Participants: This study followed a cross-sectional, mixed method and exploratory approach. The study was approved by the institute doctoral committee and adhered to ethical codes. As it attempted to explore the conceptualisation of self among lay people, the criteria for recruiting participants were not very strict. Adults from a community sample; within the age range of 20 to 60 years, having 12 years of formal education with an ability to read, write and speak either Hindi or English, were invited for the participation. All selected participants were briefed about the study's nature and objectives and their written informed consent was taken before beginning the study. The resultant sample recruited from an urban area of North India included 240 respondents (136 males and 104 females) with Hindi as their mother tongue, although many choose to respond in the English version of the questionnaire. The average age was 38.17 years $(\mathrm{SD}=11.45$ years $)$ and their age range was further subdivided into different age groups $(20-30=$ young adults; $31-40=$ adulthood; 41-50 = middle adulthood; 51-60 = late adulthood). Participants were predominately Hindu (85\%) and living with their families (65\%). More than half of them were educated upto post-graduation (55\%) and married (53\%). Among them, many reported that they were productively employed (44\%). Fewer participants reported annual family income of 2-5 lakhs per annum (37\%) and the rest reported family income ranging from 6-12 lakhs per annum (1 lakh Indian rupees is approximately equivalent to 1445 USD).

\section{Measures}


Personal Data-Sheet: For collecting demographic information, such as age, gender, educational level, occupation, religion, socio-economic background, marital status and current living status, this sheet was used.

Twenty Statements Test (TST, Kuhn and McPartland 1954): This is an unstructured, easy to administer standardised test meant for capturing spontaneous self-descriptions directly. It has been widely used in cross-cultural research due to its simple instructions, which is less likely to give room for cultural bias (Driver 1969; Dhawan et al. 1995; Carpenter and Meade-Pruitt 2008). In this test, respondents give twenty different statements in response to the question "Who Am I?" by completing the prompt of "I am..." Variations have been reported in administering TST as well as analysing the responses obtained though TST (Grace and Crammer 2003; Carpenter and Meade-Pruitt 2008). For the current study, participants were asked to finish as many statements as they can, within 1200 seconds. The statements were later thematically analysed. TST has been described as a reliable and valid research tool in various studies (Driver 1969; Dhawan et al. 1995; Grace and Crammer 2003; Hihara and Sugimura 2017).

Ahamkara Questionnaire (AQ, Raj 1993): This questionnaire is rooted in the description of self, as given in the Indian psychological literature, especially in the Vedanta school. With 18 items, this questionnaire captures ahamkara on four dimensions, namely identification (e.g., "I _like wearing uniforms and badges because they make me feel proud to be a member of the organization they represent.") and individuality (e.g., "I__ feel that I should be developing my unique capabilities."), both of which had 5 items each. Further, agency (e.g., "I_ attribute the outcome of my actions to my own choices and efforts.") and separation (e.g., "I _ feel I am different from others.") had 4 items each. These items were presented in a 'fill in the blanks' format, with 4 alternative responses: "Always", "Often", "Sometimes" and "Rarely". Some items 
were reverse coded and subsequently the total AQ score and sub-scale scores were calculated. The possible total AQ score ranges from 18-72, with higher scores reflecting higher levels of ahamkara. In a previous study, good internal consistency has been reported (Salagame and Raj 1999). In the current study, the Cronbach's alpha value of overall AQ was at 0.55 . The internal consistency reliabilities of subscales identification, individuality, agency and separation were at $0.52,0.24,0.30$ and 0.30 , respectively.

Procedure: A questionnaire booklet, both in English and Hindi versions and in paper and webbased format was developed. For Hindi version, questions were first translated (Hindi) and then back- translated (English) with the help of two subject experts knowing both the languages. Back-translated version was compared with the original for any discrepancies, and any distorted meaning or unclear sentences were corrected through discussion for reaching a final version. These booklets were given to those participants who gave written informed consent. Since the questionnaires had self-report format, it was either filled in by the participants in the presence of the researcher (first author), or was given to them to be collected later, or a soft copy was emailed to be filled and sent back. This choice of language and format was based on a participant's preference and convenience. Their queries were clarified personally or over phone. Within the sample, 130 participants opted for English, 103 for Hindi and 7 chose web-based (English) version of the questionnaire booklet.

Data analysis: Each statement on TST was analysed using thematic analysis (Braun and Clarke 2008). Rather than using the coding scheme by Kuhn and McPartland (1954), statements were analysed for any emergent themes. References to Indian model of ahamkaral ego and self was also kept in mind. Both researcher and the supervisor (second author) coded responses independently and discussed any differences in the coding scheme to reach a consensus, for 
establishing inter-rater reliability. Additionally, the frequency of qualitative themes was calculated. Quantitative data was cleaned, and no missing value was reported. Subsequently, after reverse scoring, the total and subscale scores were calculated. Since AQ scores were skewed so after employing descriptive analysis, non-parametric statistics were applied for the quantitative analysis. Mann-Whitney U test, ANOVA and Post hoc analysis with Bonferroni correction were calculated for comparing scale scores with respect to the gender and age groups.

\section{Results}

In this section, results of both qualitative and quantitative analysis from the TST and the ahamkara questionnaire are presented, respectively.

Qualitative themes from Twenty Statements Test: In TST, different respondents filled different number of blanks as a response to "Who I am?" leading to the total number of obtained themes (2787) different from the total number of participants $(\mathrm{N}=240)$. These themes were grouped under five categories; namely, individuality, belongingness, separation, agency and spiritual/ transpersonal. Given below are some verbatim responses quoted to illustrate various thematic categories. Some responses $(16,1 \%)$ could not be grouped in any of the categories.

Individuality (f=1267, 45\%): This category of themes included responses where possessing unique individual traits was conceived as a description of self. It included three sub-categories: mental-emotional qualities, interpersonal skills and bodily features. Within the sub-category of mental-emotional qualities $(855,31 \%)$ responses highlighting one's belief in having certain mental abilities or emotional characteristics that made an individual exclusive, were included. Statements like "I am genius.", "I am able to read people.", and "I am multitasking." depicted mental abilities and responses like "I am content.", "I am moody." or "I am short-tempered." expressed emotional characteristics. Some participants believed that they are unique in terms of 
their interpersonal skills $(319,11 \%)$ and interactions with others. For example, one participant mentioned, "I am a girl who respects every elder." Another participant accepted, "I give particular attention to children of the deprived class." Some of them described themselves using bodily features $(93,3 \%)$ like body-type, skin, height etc. For example, "I am fat.", "I am dusky.", "I am 6 feet 1 inch tall."

Belongingness (f=577, 21\%): Another major category that covered many of the responses was belongingness. It involved responses suggesting attachment with the immediate environment along with strong identification and sense of ownership. Statements, such as "I am a mother.", "I am a friend.", "I am a teacher." indicated attachment with certain roles. When participants used statements like "I am an IITian." or "I am a PhD scholar." to define themselves, it showed their identification with a group. On the other hand, responses like "I am close to my sister." ,I am devoted to my children." where specific kind of relationship with a significant other was cited as self-explanation, indicated sense of ownership.

Separation (f=423, 15\%): This theme captured a self-sense that emphasised the difference between self and others and categorising the world in 'us versus them' based on some characteristics. For example, responses like "I am a woman.", "I am a vegetarian.” or "I am a Bihari." displayed a sense of separation. It is important to clarify that separation differs from belongingness and individuality thematic categories. While separation requires people to separate themselves from others using some principles (e.g., assumptions, characteristics), in belongingness, they associate with a group without bothering about those left outside. However in many contexts, these two are closely linked as some group memberships automatically separate an individual from others (Darmanin 2018). Finally, individuality suggests that self is established on those traits which make one unique. 
Agency (404, 14\%): While sharing self-related information, some participants linked their selfsense with personal efficiency and instrumentality. This theme included statements like, "I am able to complete my work on time.", "I am the one who, I believe, brings change to my parents' thought." or "I am responsible for all important departmental works." etc.

Spiritual/ transpersonal $(\mathbf{1 0 0}, \mathbf{4 \%})$ : There were a small number of statements where self was perceived as connected with the larger whole or with a transpersonal entity. For instance, "I am the part of universe.", "I am a soul loved by Shiv Baba." (name of Hindu God), "I am more than the body, the consciousness." etc. were seen as spiritual/ transpersonal statements.

Age related thematic analysis (supplementary analysis): Since the study included a wide agerange, themes recurring in statements were also investigated in different age groups (supplementary table). It was found that ideas of individuality (33\%), separation (29\%) and agency (27\%) were common amongst participants from the 20-30 years age group. However, statements indicating individuality and agency thematic category became less frequent with the increase in age. On the other hand, self-statements included in the separation thematic category showed an interesting pattern. Unlike 30-41 years and 51-60 years age groups that used fewer statements related to sense of separation, participants in 41-50 years age group had slightly higher frequency of this theme in their sense of self. Similarly, an increase in statements suggesting belongingness $(26 \%)$ was also found in the middle-aged adults (41-50 years) before again decreasing in late adulthood (51-60 years). Interestingly, self-definitions of participants from the 51-60 years age group involved more spiritual/ transpersonal terms (48\%). Such reflections about self were fewer among young adults (15\%), though their frequencies increased with age (31-40 years: $18 \%$ and $41-50$ years: $19 \%)$.

\section{Quantitative results from Ahamkara Questionnaire (AQ):}


A measure of ahamkara was also administered to the same respondents. Cronbach's alpha value for AQ was less than the prevalent acceptable value $(\geq 0.70)$ (Lance, Butts and Michels 2006; Taber 2018). Since it has been argued that a high alpha value does not confirm the reliability of a research tool (Taber 2018), a decision was taken to proceed with the analysis using existing data. Table 1 shows that participants were at the moderate levels of ahamkara $(\mathrm{M}=44.80)$, as the mean is almost the same as the median. However, a slight positive skewness suggests that few participants would have scored much higher on total AQ. Likewise, some participants would have scored higher on sub-scales of individuality $(\mathrm{M}=12.85)$ and separation $(\mathrm{M}=9.33)$ as indicated by the lower mode. The agency sub-scale $(M=9.81)$ scores had nearly a normal distribution. For identification $(\mathrm{M}=12.80)$ sub-scale, mean and median were also similar; however, some negative skewness was present with a higher mode, indicating a few respondents would have scored lower on this aspect. Figure 2 represents the graphical distribution of total scores on AQ. Table 2 shows that males $(M=45.57, S D=5.54)$ were significantly $(U=5999, p$ $<0.05)$ higher on total ahamkara level as compare to females $(\mathrm{M}=43.78, \mathrm{SD}=7.04)$. Although they did not differ significantly on sub-scales, there was a trend $(p=0.09)$ suggesting that men were relatively higher on the dimension of agency (Table 3).

As shown in Table 4, different age groups displayed different levels of ahamkara [F (3, $236)=8.43, \mathrm{p}<0.001]$. Post hoc analysis with Bonferroni correction revealed that the 20-30 years age group had significantly higher ahamkara scores, than the 51-60 years age group $(p=0.001)$ and the 41-50 years age group $(p=0.007)$. However, this difference was not significant with 31 40 years age group $(p=0.36)$. Participants from 31-40 years age group showed a significant difference in AQ mean score, in terms of higher ahamkara, only from 51-60 years age group ( $p$ $=0.03)$. 
All four age groups were also assessed on sub-scales and it was found that they differ significantly only on individuality $[\mathrm{F}(3,236)=13.25, \mathrm{p}<0.001]$ and separation sub-scales $[\mathrm{F}(3$, $236=4.82, \mathrm{p}<0.003$ ]. Table 4 suggests that participants within the age range of $20-30$ years scored highest on individuality and separation $(\mathrm{M}=13.94 ; \mathrm{M}=9.91)$ and participants from 5160 years age group scored the lowest $(\mathrm{M}=11.47 ; \mathrm{M}=8.39)$ on these sub-scales.

\section{Discussion}

The present study is an attempt to explore the concept of self in contemporary urban India and also to document similarities and differences from the traditional Indian ideas of self. This was done through a mixed method design, studying personal meanings and beliefs associated with ego and identity using a semi-structured questionnaire and a standardised Indian measure of ego or ahamkara to assess its current levels, among urban educated adults. Such mixed method research may help in thoroughly exploring and deeply understanding a research topic, when both data sets are used as complementary (Moffatt et al. 2006). However, this combination of methods may pose some difficulties, such as inconsistency in findings and the following discussion is an attempt to address this issue and explain any inter-method discrepancy. It may be observed that the terms assigned for most of the thematic categories resemble the dimensions explained in the ahamkara questionnaire, which is based on the Vedantic school of Indian tradition. It may be explained by the fact that not only the researchers were exploring similarities and differences with the traditional ideas of self, but also that such Vedantic notions seem to be popular in Indian culture, even in contemporary times (Gautam and Jain 2010).

The findings from qualitative data indicated that generally, self-sense includes more than one sub-component of ahamkara, although some components may dominate depending on one's occupation and current life circumstances (Salagame et al. 2005; Salagame 2011). Further, 
individuality was the commonest theme where one's uniqueness related to mental-emotional qualities, interpersonal skills and bodily features was emphasised. This idea of individuality is similarly present in the Vedantic literature, indicating a strong sense of autonomy, derived from unique abilities (Salagame 2011). In the current study, the individuality themes decreased with age, especially the bodily and mental-emotional qualities, while there was lesser decline in the sense of individuality based on interpersonal skills. On the other hand, belongingness, which was indicated in terms of close linking to a certain role, group or significant other, became the second most frequent category. In Vedantic literature, such identifications may be based on association and companionship, attractions and attachments along with ownership of worldly objects (Salagame et al. 2005). In current data, the majority spoke about people and social groups, whereas identification with material objects as a means of self-construal was relatively infrequent. Therefore, the thematic category was named as belongingness, instead of identification. The scores on identification sub-scale were negatively skewed, suggesting that few respondents may have had low levels of identification, which has generally been encouraged in the Indian tradition. However, lowering of identification or cultivation of such non-attachment requires constant efforts and volition, and few people may practice it (Sahdra, Shaver and Brown 2010). Even those who are less identified with material objects may still find non-identification harder with people and social life as well as for positive experiences in general, especially when living a regular community life (Smrithi, Agrawal and Kapani 2017). Understanding the levels of identification in monks living in a monastery, or those living in solitude may provide new insights related to the sense of identification.

The separation category reflected the mental distance which people experience between self and others based on certain facts of life. This tendency to feel a strong sense of boundary 
between self and others (duality) has been discussed in Vedantic literature (Salagame 2011). While it was not the commonest thematic category, it may reflect the most problematic one. Potentially the sense of separation is behind various difficulties of humanity, from wars to discrimination. It may also contribute to isolation from the rest of humanity, which leads to decreased self-compassion and increased self-criticism (Neff 2003). An interesting pattern on separation sub-scale scores was also observed across age groups, where it decreased initially (in 31-40 years) and then increased (in 41-50 years) before further decreasing (in 51-60 years). Probably with growing age, people get preoccupied with managing career-demands and family responsibilities and thus start feeling distant from the larger community. During middle adulthood, people may even experience a growing sense of separation from their spouses and children, in addition to accepting the ageing and mortality as a part of the developmental task (Colarusso 1998).

It is important to note that belongingness and separation may also be viewed as two sides of the same coin. Although within belongingness, one stresses on drawing similarities with others and, separation focuses on how one is different from others, both require the real or imagined presence of others. Moreover, it may be difficult to tease out these constructs since both are often present together within the self-concept.

The quantitative findings indicated a moderate level of individuality and separation among participants; however, positive skewness of scores on both aspects implies that few participants have a much higher sense of individuality or separation than the rest. It has been proposed that advanced yogi-meditators as well as patients diagnosed with any personality disorder and concomitant difficulties with self, may experience extreme individuality and/or separation (Salagame et al. 2005). Since study participants were recruited from the community, 
their mean scores were still not extreme either on individuality or separation sub-scales. As per Salagame (2011) these aspects of ahamkara also corresponds to the idea of separationindividuation, as given by Margaret Mahler (1975). Individuation marks the development of autonomy, in the form of independent decision-making and separation allows one to make a distinction between self and others. These two processes are suggested to be intertwined and complementary, and help in forming one's identity. It has also been argued that this process starts early in childhood and may extend unto adulthood (Frank, Avery and Laman1988). Within the current sample, a large proportion of participants were young adults who may be inclined towards developing an autonomous identity. This was also indicated in thematic analysis, where individuality was the most frequent self-concept category amongst younger aged participants (20-30 years). These results differed from the findings of Dollinger and Dollinger (2003), where they found that people in their younger years (18-27 years) reflect less individuality, due to their poorly differentiated self-representations. However, in the current study young participants seemed to believe in personal uniqueness and quality of being irreplaceable. It may also explain why they displayed a sense of separation and agency in their self-definitions. Possibly while marking their uniqueness, they recognised themselves as action-agents who are separate from others. With ageing the sense of self becomes wider, encompassing significant others, family and community within its boundaries, and having a decreased sense of individuality and separation. Therefore, older adults had lower scores on individuality and separation sub-scales. The other explanation may be that these differences occurred due to the cohort effect. Perhaps, older people are more influenced by classical Indian thoughts, while younger people seem to be guided by an increasingly individualistic culture focused on self-interest and personal satisfaction. Although overall spiritual/ transpersonal concepts were few, its proportion was higher in the self- 
definitions of the 51-60 years age group. A self-sense that involves spirituality requires a low level of ahamkara, which may need volition and ongoing effort. Such self-sense is similar to what Indian mystic Ramakrishna Paramhansa called 'ripe-ego' (Sri Ramakrishna 1872/2008, p. 41) and was reported by few, usually in the older age group. These findings support the notion that spiritual growth is accelerated in the second half of adult life (Wink and Dillon 2002). As Jung $(1943 ; 1964)$ pointed out that during midlife (around 50s), people usually start their inner journey and explore the spiritual aspects of self, which was ignored during young adulthood. Moreover, increased awareness of mortality may also facilitate this inner exploration.

The fourth theme was agency, which included those statements where self-sense was intimately linked with one's control over tasks and having a sense of personal efficacy, overlapping with similar Vedantic idea of work (Salagame 2011). Previous studies have suggested that personal agency enables an individual to differentiate between self-generated thoughts and actions, and those created by others, thus leading to self-other distinction and eventually awareness of personal identity (Salagame et al. 2005; Balconi 2010). While agency was a less frequent thematic category, it further decreased a bit with age. Interestingly a significant gender differences were found in the ahamkara level. Although no significant gender difference was observed on any of the sub-scales, men were higher (at trend level) on agency sub-scale. The cultural emphasis on goal pursuit for men, more than for women, could be an explanation for such results. Similar patterns have been reported in few earlier works, where men had higher egoism and longings for worldly objects (Gaur 1994; Bhushan and Jha, 2005; Bönte and Jarosch 2011; Khanna et al. 2013). The sense of agency or doer-ship is closely related to outcome orientation, which involves performing actions for desired outcomes or rewards. This linking of action with specific goals is not only seen as an obstacle in the spiritual journey, but 
was also found to be associated with lowering of well-being (Street 2002; Hadley and MacLeod 2010; Banth and Talwar 2012). On the other hand, a healthy sense of agency leading to selfdirection may contribute to higher well-being (Moore 2016). Doing work with less focus on outcomes, within ethical boundaries, and for the aim of social welfare is emphasised in classical Indian teachings (Salagame 2008). It may be noted that most of the participants were able to point out the major factors contributing to their self-definitions. This clarity in self-understanding is an indication of higher self-regard and trust in personal abilities (Guerrettaza and Arkin 2015). Such ahamkara based self-knowledge is still considered limited in Indian contemplative traditions, it may lead to transformation through meditative practices (Jakubczak 2004).

The self-descriptions also diverged from the popular view that Indian self is predominantly interdependent and collectivistic (Misra 2001; Li et al. 2006) and supported the perspective that Indian self, especially in an urban landscape, is patterned upon co-existing threads of individuality and collectivism (Mascolo, Misra and Rapisardi 2004). Even the traditional Indian approach promotes reconciling various views. For instance, both nonattachment and working for social-welfare have been emphasised simultaneously and such ability to integrate different values and harmonise diversity contributes to mental health (Narayanan and Rao 2018). In order to maintain social harmony, norms in Indian society discourage higher level of ego (Kakar 1982) and therefore, in current sample of community adults, only moderate levels of ahamkara were indicated (total AQ and sub-scale scores).

Implications, limitations and future directions: This study establishes the traditional Indian model of ego/ identity, in terms of ahamkara and its components such as individuality, belongingness, separation and agency, even in a contemporary urban educated sample. It broadly validates an alternative view of human nature, which is different from the popular Western 
framework. Although limited in number among participants, qualitative results also confirmed the presence of a spiritual component (ripe ego) in self-concepts, which was higher in older age group. This supported the idea that people turn inwards as they age; however, due to a possible cohort effect, it needs to be tested using longitudinal research in future. The age and gender differences in the level of ahamkara confirmed that life experiences and socio-cultural context shape identities (Stryker, Serpe and Hunt 2005). Moreover, given the overlap between belongingness and separation, future studies may consider the benefits of treating them as a single category.

Given that a majority of respondents in this community-based sample had moderate levels of ahamkara, one may consider that contemporary urban Indians are able to maintain a sense of interdependence, even when they desire for the individuality. These results have personal and social implications. Understanding how people integrate diverse values within oneself, may provide insights into the process of maintaining inner harmony while facing social and life challenges. Future studies may not only explore the self-concepts of Indians from different social and cultural settings, but may also compare them with Western individuals on dimensions of ahamkara.

Few researchers have reported that high ahamkara correlates with mental health issues (Rekha 1995; Salagame and Raj 1999). Future studies may examine whether clinical variables differ for ahamkara level and the process of maintaining positive mental health by balancing personal needs with family and social welfare. Such findings may be used as a guide for identifying problematic patterns in self-description and designing interventions, accordingly. A Longitudinal study with a clinical population and healthy meditators may provide deeper insights into the full spectrum of mental health. As Indian tradition is varied in itself and has multiple 
schools within, future researchers may also explore 'self' from other Indian contemplative perspectives, such as Buddhism and Jainism.

There are some important considerations and limitations of the present study. All participants were from an urban community, and they were predominantly Hindu males; thus, the generalisability of results is limited. Moreover, since the information on meditative practices of study participants was not available, it is possible that some of them practiced meditation and that would have influenced their ahamkara levels as lower levels of ahamkara have been found in meditators (Raj 1993; Parimala 2001). Further, assigning a time-limit for responding to TST may have restricted the openness and depth in responses. Although it was more than the original time constraint, that is 720 seconds as determined by Kuhn and McPartland (1954), it may have made participants feel rushed or stressed.

The free format of TST overcame the limitation associated with rating scales, but despite that, it has limits of exploration. Thus, while self-related data varied; however, they were less rich as compared to information gathered through an in-depth interview. Moreover, thematic analysis based on gender has not been done. While overall there was a difference, the sub-scales did not differ significantly.

The low reliability of AQ scale and its sub-scales in the current study is another limitation. Although some studies have considered Cronbach's alpha value of 0.55 not being problematic (Berger and Hänze 2015; Griethuijsen et al. 2015; Taber 2018), still quantitative results should be interpreted with caution. Possibly, items within a sub-scale may not be fully tapping a sub-component of ahamkara; however, this was the only scale available for assessing Indian model of ego. Therefore, future research may consider revising it for the contemporary population. Contemplative traditions emphasise first-person research for deeper insights into the 
human mind and mental phenomena, however, this was a limitation of the current research since a research journal could not be maintained regularly for reflexivity.

\section{Summary and conclusion}

The current study aimed to explore and document the common subjective ideas and beliefs related to self among urban educated Indians in modern times. It further studied its overlap with traditional Vedantic model of ego, known as ahamkara. A cross-sectional, mixed-method study was conducted with 240 participants, using a semi-structured questionnaire along with a standardised scale of ahamkara. Results suggested that all components of ahamkara were present in the self-concepts; however, they seemed to be arranged in an order of decreasing frequency. The thematic category of Individuality was the commonest, followed by belongingness, separation and agency. Spirituality based self-concepts and ideas of transcending ahamkara were few, although they increased with age, along with decrease in individuality, separation and slight decrease in agency. The qualitative results have established that all four sub-components of ahamkara: individuality, separation, agency and belongingness; exist as a part of the self-concepts in a community sample. These findings have shown overlap with the classical Indian ideas, upon which the ahamkara questionnaire is also built. The presence and increase in the frequency of spiritual 'ripe ego' with age were also observed. The findings also indicate that the identification component was predominantly limited to the interpersonal-social realm in this sample, thus named as belongingness. Given the overlap between belongingness and separation, this may be considered as a single category.

The quantitative results also demonstrated that lay community has moderate levels of ahamkara, which also seems to decrease with age. Furthermore, males were found to have higher levels of ahamkara than females. Current work also supported co-existence of 
individualistic and relational-contextual self in Indians and diverged from the idea that Indian self is purely interdependent in nature. It is recommended that researchers should take note of the current understanding of self in Indian context, while planning any intervention in the area of mental health.

\section{References}

Balconi, M., 2010. The sense of agency in psychology and neuropsychology. In M. Balconi, ed. Neuropsychology of the sense of agency: from consciousness to action. New York: Springer, pp. 3-22.

Banth, S. and Talwar, C., 2012. Anasakti, the Hindu ideal, and its relationship to well-being and orientations to happiness. Journal of Religion \& Health, 51, 934-947. https://doi.org/10.1007/s10943-010-9402-3

Bauer, J.J., and Wayment, H.A., 2008. The psychology of quieting the ego. In: H.A. Wayment and J.J. Bauer, eds. Transcending self-interest: psychological explorations of the quiet ego. Washington, DC: American Psychological Association, pp. 7-19.

Baumeister, R.F., Campbell, J.D., Krueger, J. I. and Vohs, K. D., 2003. Does high self-esteem cause better performance, interpersonal success, happiness, or healthier lifestyles? Psychological Science in the Public Interest, 4 (1), 1-44. https://doi.org/10.1111/1529-1006.01431

Bhushan, L. I. and Jha, M. K., 2005. Developing test of asakti and anasakti. Indian Journal of Psychometrics and Education, 36 (1), 3-9.

Berger, R. and Hänze, M., 2015. Impact of expert teaching quality on novice academic performance in the jigsaw cooperative learning method. International Journal of Science Education, 37 (2), 294-320. https://doi.org/10.1080/09500693.2014.985757

Bönte, W. and Jarosch, M., 2011. Gender differences in competitiveness, risk tolerance, and other personality traits: do they contribute to the gender gap in entrepreneurship? In Schumpeter Discussion paper 2011-2012 at Schumpeter School of Business and Economics, the University of Wupperta. http://conference.iza.org/conference_files/EntreRes2012/7735.pdf . accessed on 10 June 2020.

Braun, V. and Clarke, V., 2008. Using thematic analysis in psychology. Qualitative Research in Psychology, 3 (2), 77-101.

Baumeister, R.F., Campbell, J.D., Krueger, J.I. and Vohs, K.D. 2003. Does high self-esteem cause better performance, interpersonal success, happiness, or healthier lifestyles? Psychological Science in the Public Interest, 4 (1), 1-44.

Burnkrant, R.E. and Unnava, H.R., 1995. Effects of self-referencing on persuasion. Journal of Consumer Research, 22 (1), 17-26. https://doi.org/10.1086/209432 
Campbell, W.K. and Buffardi, L.E., 2008. The lure of the noisy ego: narcissism as a social trap. In: H.A. Wayment and J.J. Bauer, eds. Transcending self-interest: psychological explorations of the quiet ego. Decade of behavior. Washington, DC: American Psychological Association, pp. 23-32. http://www.sakkyndig.com/psykologi/artvit/campbell2008.pdf. accessed on 12 June 2020.

Carpenter, S. and Meade-Pruitt, S., 2008. Does the twenty statements test elicit self-concept aspects that are most descriptive? World Cultures eJournal, 16 (1). https://escholarship.org/uc/item/466355d4. accessed on 15 June 2020.

Chandur, J. and Sriram, S., 2018. Anasakti as interpreted and practised in the Bhakti tradition. Psychological Studies, 63 (2), 153-162. https://link.springer.com/content/pdf/10.1007/s12646017-0435-5.pdf

Chang, J.H., Hodgins, H. S., Lin, Y.C. and Huang, C.L., 2014. On the flexibility of the automatic us-them divide. In: N. Weinstein, ed. Human motivation and interpersonal relationships: theory, research, and applications New York: Springer Science + Business Media, pp. 97-119. https://doi.org/10.1007/978-94-017-8542-6_5

Colarusso, C.A., 1998. A developmental line of time sense: in late adulthood and throughout the life cycle [Abstract]. The Psychoanalytic Study of the Child, 53 (1), 113-40. https://doi.org/10.1080/00797308.1998.11822479

Collins, A. and Desai, P., 1986. Selfhood in Context: some Indian solutions. In: M. White and S. Pollack, eds. The cultural transition. New York: Routledge and Keegan Paul, pp. 261-290.

Dalal, A. and Misra, G., 2010. The core and context of Indian psychology. Psychology and Developing Societies, 22 (1), 121-155. https://doi.org/10.1177/097133360902200105

Darmanin, M., 2018. The 'us' against 'them': how group identity can divide us. Therapy Works [Blog]. accessed on 19 June 2020, https://www.therapyworks.com.mt/posts/2018/12/10/the-usagainst-them-mentality-how-group-identity-can-divide-us/

Dhawan, N., Roseman, I.J., Naidu, R.K., Thapa, K. and Rettek, S.I., 1995. Self-concepts across two cultures: India and the United States. Journal of Cross-Cultural Psychology, 26 (6), 606621. https://doi.org/10.1177/002202219502600606

Dolichan, K.M., 2007. Human models and developmental efforts. Paper presented at National Seminar on Indian Psychology: Theories and models, SVYASA, Bangalore, India, 26-28 December 2007. https://www.ipi.org.in/texts/nsip/nsip-abstracts/dolichankm.php

Dollinger, S.J. and Dollinger, M.C., 2003. Individuality in young and middle adulthood: an autophotographic study. Journal of Adult Development, 10 (4), 227-236. https://doi.org/10.1023/A:1026003426064

Driver, E., 1969. Self-Conceptions in India and the United States: a cross-cultural validation of the twenty statements test. The Sociological Quarterly, 10 (3), 341-354.

Frank, S., Avery, C. and Laman, M., 1988. Young adults' perception of their relationships with their parents: individual differences in connectedness, competence and emotional autonomy. Developmental Psychology, 24 (5), 729-737. 
Gaur, S. M., 1994. 'A study of the concepts of ahamkara and ego functions in males and females', Master's Dissertation, University of Mysore, India.

Gaur, S.D., 2011. Why I am here? Implications of self and identity for conceptualising motivation. In: R.M.M. Cornelissen, G. Misra and S. Varma, eds. Foundations of Indian psychology. New Delhi: Pearson Education, pp. 401-414.

Gautam, S. and Jain, N., 2010. Indian culture and psychiatry. Indian Journal of Psychiatry, 52 (7), 309-313. $\quad$ https://www.ncbi.nlm.nih.gov/pmc/articles/PMC3146223/ http://www.indianjpsychiatry.org/text.asp?2010/52/7/309/69259

Grace, S.L. and Cramer, K.L., 2003. The elusive nature of self-measurement: the self-construal scale versus the twenty statements test. The Journal of Social Psychology, 143 (5), 649-668. https://doi.org/10.1080/00224540309598469

Griethuijsen, R.A.L.F., Eijck, M.W., Haste, H., Brok, P.J., Skinner, N.C., Mansour, N., Gencer, A.S. and BouJaoude, S., 2015. Global patterns in students' views of science and interest in science. Research in Science Education, 45 (4), 581-603. https://doi.org/10.1007/s11165-014$\underline{9438-6}$

Guerrettaz, J.and Arkin, R.M., 2015. Who Am I? How asking the question changes the answer. Self and Identity, 14 (1), 90-103. https://doi.org/10.1080/15298868.2014.955049

Hadley S.A. and MacLeod, A.K., 2010. Conditional goal-setting, personal goals and hopelessness about the future [Abstract]. Cognition and Emotion, 24 (7), 11911198. https://doi.org/10.1080/02699930903122521

Heppner, P.P., 2006. The benefits and challenges of becoming cross-culturally competent counselling psychologists: presidential address. The Counselling Psychologist, 34 (1), 147-172. https://doi.org/10.1177/0011000005282832

Havik, G., Elands, B.H.M. and Koppen, C.S.A.V., 2015. An encounter with one's deeper self and energy: a phenomenological study among spiritually engaged individuals in the Netherlands. Ecopsychology, 7 (2), 75-83. https://doi.org/10.1089/eco.2015.0007

Hihara, S. and Sugimura, K., 2017. An examination of negative identity of adolescents using the twenty statements test: quantitative and qualitative analyses. Japanese Journal of Developmental Psychology, 28 (2), 84-95.

Jakubczak, M., 2004. Towards knowing ourselves: classical yoga perspective. Journal of Human Values, 10 (2), 111-116. https://doi.org/10.1177/097168580401000204

Jakubczak, M., 2013. The sense of ego-maker in classical sāṃkhya and yoga: reconsideration of 'ahamkāra' with reference to the mind-body problem. In: G. Misra, ed. Psychology and Psychoanalysis. History of Science, Philosophy. New Delhi: Munshiram Monoharlal. pp. 291308. https://philarchive.org/archive/JAKPP-4

Jung, C. G., 1943. On the psychology of the unconscious. In: H. Read, M. Fordham, and G. Adler, eds, Jung: Collected Works (Vol. 7). New Jersey: Princeton University Press, pp. 3-17.

Jung, C. G. (1964). Man and his symbols. New York: Laurel. 
Kakar, S., 1982. Shamans, mystics and doctors: a psychological inquiry into India and its healing traditions. New Delhi: Oxford India Press.

Khanna, P., Singh, K., Singla, S. and Verma, V., 2013. Relationship between triguna theory and well-being indicators. International Journal of Yoga-Philosophy, Psychology and Parapsychology, 1 (2), 69-74. http://www.ijoyppp.org/text.asp?2013/1/2/69/157888

Kuhn, M. H. and McPartland, T. S.,1954. An empirical investigation of self-attitudes. American Sociological Review, 19 (1), 68-76.

Kumar, S.K.K., 2008. Indian thought and tradition: a psycho-historical perspective. In: K.R. Rao, A.C. Paranjpe and A.K. Dalal, eds. Handbook of Indian psychology. New Delhi: Cambridge University Press, pp. 19-52.

Lance, C.E., Butts, M.M. and Michels, L.C., 2006. The sources of four commonly reported cutoff criteria: what did they really say. Organizational Research Methods, 9 (6), 202-220.

Leary, M.R., 2007. Motivational and emotional aspects of self. Annual Review of Psychology, 58 (1), 317-344. https://doi.org/10.1146/annurev.psych.58.110405.085658

Li, H. Z., Zhang, Z., Bhatt, G. and Yum, Y.O., 2006. Rethinking culture and self-construal: China as a middle land. The Journal of Social Psychology, 146 (5), 591-610.

Mahler, M., Pine, F. and Bergman, A., 1975. The psychological birth of the human infant. New York: Basic Books.

Mascolo, M. F., Misra, G. and Rapisardi, C., 2004. Individual and relational conceptions of self in India and the United States. In: M. F. Mascolo and J. Li, eds. Culture and developing selves: beyond dichotomization. San Francisco: Jossey-Bass, pp. 9-27.

Moffatt, S., White, M., Mackintosh, J. and Howel, D., 2006. Using quantitative and qualitative data in health services research-what happens when mixed method findings conflict? $B M C$ Health Services Research, 6, 28. https://doi.org/10.1186/1472-6963-6-28

Moore, J.W., 2016. What is sense of agency and why does it matter? Frontiers in Psychology, 7, 1272. https://doi.org/10.3389/fpsyg.2016.01272

Mills, K.L., 2011. Experiential self-referential processing \& autobiographical memory retrieval: a preliminary look. PSU McNair Scholars Online Journal, 5 (1), 198-221. http://archives.pdx.edu/ds/psu/8791

Misra, G., 2001. Culture and self: implications for psychological inquiry. Journal of Indian Psychology, 19 (1-2), 1-20.

Misra, G., 2010. The cultural construction of self and emotion: implications for well-being. In: R. Schwarzer and P.A. Frensch, eds. Personality, human development and culture: international perspectives on psychological science (Vol. 2). New York: Psychology Press, pp. 95-111.

Misra, G. and Mohanty, A.K., 2002. Introduction. In: G. Misra and A.K. Mohanty, eds. Perspectives on indigenous psychology. New Delhi: Concept Publication Company, pp. 13-33.

Misra G., Paranjpe A.C., 2012. Psychology in modern India. In: R.W. Rieber, ed. Encyclopedia of the history of psychological theories. New York: Springer, pp. 881-892. 
Narayanan, G. and Rao, K., 2018. Personality disorders in the Indian culture: reconsidering selfperceptions, traditional society and values. Psychological Studies, 63, 32-41. https://doi.org/10.1007/s12646-017-0437-3

Neff, K., 2003. Self-compassion: an alternative conceptualisation of a healthy attitude toward oneself. Self and Identity, 2 (2), 85-102.

Paranjpe, A.C., 2002. Self and Identity in Modern Psychology and Indian Thought. New York: Kluwer Academic Publishers.

Primal, N., 2001. 'Ahamkara and ego functions among short term meditators and long term meditators', Master's Dissertation, University of Mysore.

Raghuram, N.V., 2007. Ego in Indian philosophy. https://www.ipi.org.in/texts/nsip/nsipabstracts/raghuramnv.php. accessed on 16 June 2020.

Raj, A., 1993. 'Meditation: transcendence of ahamkara or disintegration of ego functions? An empirical investigation on the concepts of ahamkara and ego functions', Master's dissertation, University of Mysore.

Rao, K.R., 2014. Indian Psychology: implications and applications. In: R.M.M. Cornelissen, G. Misra and S. Varma, eds. Foundations and applications of Indian psychology. New Delhi: Dorling Kindersley Pvt. Ltd., pp. 3-16.

Rao, K., and Paranjpe, A., 2016. Psychology in the Indian Tradition. New Delhi: Springer Pvt. Ltd.

Reddy, V.M. 1990. Integral yoga psychology: the psychic way to human growth and human potential. Hyderabad: Institute of Human Study.

Reddy, S., 2014. Spiritual conversion in the Bhagavad Gita: a psychoanalytic study. In: J. Gale, M. Robson and G. Rapsomatioti, eds. Insanity and divinity: studies in psychosis and spirituality. New York: Routledge, pp. 131-149.

Rekha, K., 1995. 'Ahamkara and ego functions among neurotics and general population', Master's Dissertation, University of Mysore, India.

Sahdra, B.K., Shaver, P.R. and Brown, K.W., 2010. A scale to measure nonattachment: a Buddhist complement to Western research on attachment and adaptive functioning. Journal of Personality Assessment, 92 (2), 116-127. https://doi.org/10.1080/00223890903425960

Salagame, K.K.K. and Raj, A., 1999. Ahamkara and ego functions among meditators and normals. Journal of Indian Psychology, 17 (1), 46-55.

Salagame, K.K.K., Raj, A., Murthy, K.P., Parimala, N., Rekha, K. and Gaur, S., 2005. Concept ahamkara: Theoretical and empirical analysis. In: K.R. Rao and S.B. Marwaha, eds. Towards $a$ Spiritual Psychology - essays in Indian Psychology. New Delhi: Samvad India Foundation, pp. 97-122.

Salagame, K.K.K., 2008. Indian thoughts and traditions: A psycho-historical perspective. In: K.R. Rao, A.C. Paranjpe and A.K. Dalal, eds. Handbook of Indian psychology, New Delhi: Cambridge University Press of India Pvt. Ltd., pp. 19-52. 
Salagame, K., 2011. Ego and ahamkara: self and identity in modern psychology and indian thought. In: R. Cornelissen, G. Misra, and S. Varma, eds. Foundations of Indian Psychology: Concepts and Theories. New Delhi: Dorling Kindersley India Pvt. Ltd., pp. 133- 145.

Salagame, K.K.K., 2013. Indian Psychology. In: K.D. Keith, ed. The Encyclopedia of Cross-Cultural Psychology (Vol. 2). New Jersey: Wiley Blackwell, pp. 1-3. https://doi.org/10.1002/9781118339893.wbeccp283. accessed on 19 June 2020.

Smrithi, M., Agrawal, J. and Kapanee, A.R., 2017. 'Association of kleshas and brahmaviharas with psychological distress and wisdom among college going youth', M. Phil Dissertation, National Institute of Mental Health and Neuro-Sciences, India.

Sri Aurobindo., 1940/ 2005. The double soul in man. In: Sri Aurobindo's The life divine. Complete works of Sri Aurobindo (Vols. 21-22). Pondicherry: Sri Aurobindo Ashram Press, pp. 231-244.

Sri Ramkrishna Paramhamsa., 1872/2008. Maya as ahamkara or egotism. In: D. Jhari, ed. Sayings of Ramkrishna Paramhamsa, New Delhi: Juggernaut Publications, pp. 115-118.

Street, H., 2002. Exploring relationship between goal setting, goal pursuit and depression: a review. Australian Psychologist, 37 (2), 95-103. https://doi.org/10.1080/00050060210001706736

Stryker, S., Serpe, R.T. And Hunt, M.O., 2005. Making good on a promise: the impact of larger social structures on commitments. In: S.R. Thye and E.J. Lawler, eds. Social identification in groups (Advances in group process, Vol. 22). Bingley: Emerald Group Publishing Limited, pp. 93-123.

Taber, K.S., 2018. The use of Cronbach's alpha when developing and reporting research instruments in science education. Research in Science Education, 48 (3), 1273-1296. https://doi.org/10.1007/s11165-016-9602-2

Wayment, H.A.,Wiist, B., Sullivan, B.M. and Warren, M. A., 2011. Doing and being: mindfulness, health, and quiet ego characteristics among Buddhist practitioners. Journal of Happiness Studies, 12 (4), 575-589. https://doi.org/10.1007/s10902-010-9218-6

Wink, P. and Dillon, M. 2002. Spiritual development across the adult life course: findings from a longitudinal study. Journal of Adult Development, 9, 79-94. https://doi.org/10.1023/A:1013833419122 
Table 1: Descriptive statistics for measure of ahamkara/ ego and its subscales ( $\mathrm{N}=\mathbf{2 4 0})$

\begin{tabular}{llll}
\hline Scales & Possible & Obtained & Mean SD Median Mode \\
& Range & Range &
\end{tabular}

\begin{tabular}{ccccccc}
\hline Ahamkara Questionnaire & $18-72$ & $22-61$ & 44.80 & 6.28 & 45 & 43 \\
Identification & $5-20$ & $5-20$ & 12.80 & 3.06 & 13 & 15 \\
Individuality & $5-20$ & $5-19$ & 12.85 & 2.38 & 13 & 12 \\
Agency & $4-16$ & $4-16$ & 9.81 & 2.45 & 10 & 10 \\
Separation & $4-16$ & $4-15$ & 9.33 & 2.33 & 9 & 7 \\
\hline
\end{tabular}

Note: Higher scores indicate higher level of ahamkara

Table 2: Mann Whitney $U$ test comparing total AQ scores for males and females $(\mathrm{N}=\mathbf{2 4 0})$

\begin{tabular}{lllllll}
\hline Scale & Groups & Mean & SD & Mean Rank & U & P \\
& & & & & & \\
\hline AQ & Male & 45.57 & 5.54 & 128.47 & \multirow{2}{*}{5988} & \multirow{2}{*}{04} \\
& Female & 43.78 & 7.04 & 110.08 & \\
\hline
\end{tabular}

Note: MWU=Mann Whitney U test. $p=2$-tailed

Table 3: Mann Whitney U test comparing AQ's sub-scales' scores for males and females $(\mathbf{N}=\mathbf{2 4 0})$

\begin{tabular}{lllllll}
\hline Scale & Groups & Mean & SD & Mean Rank & U & \multicolumn{1}{l}{} \\
\hline \multirow{2}{*}{ Identification } & Male & 13.07 & 3.14 & 126.75 & 6222.500 & .11 \\
& Female & 12.44 & 2.94 & 112.33 & & \\
\multirow{2}{*}{ Individuality } & Male & 13.05 & 2.33 & 126.40 & 6270.000 & .13 \\
\multirow{2}{*}{ Agency } & Female & 12.60 & 2.42 & 112.79 & & \\
\multirow{2}{*}{ Separation } & Male & 10.07 & 2.26 & 127.14 & 6169.500 & .09 \\
& Female & 9.48 & 2.66 & 111.82 & & \\
& Male & 9.39 & 2.44 & 121.93 & 6878.000 & .71 \\
\hline
\end{tabular}


Table 4: Difference in AQ total scores and its sub-scales scores based on Age ( $N=240)$

\begin{tabular}{lllll}
\hline Age groups (in years) & $\mathbf{n}$ & Mean (SD) & \\
\hline \multirow{20-30}{*}{} & & AQ & Individuality & Separation \\
\cline { 3 - 5 } & $\mathbf{7 7}$ & $47.14( \pm 4.83)$ & $13.94( \pm 2.06)$ & 9.91 \\
$\mathbf{3 1 - 4 0}$ & $\mathbf{6 1}$ & & & $( \pm 2.32)$ \\
& & $45.20( \pm 6.12)$ & $12.95( \pm 2.29)$ & 9.20 \\
$\mathbf{4 1 - 5 0}$ & $\mathbf{5 1}$ & & & $( \pm 2.28)$ \\
& & $43.59( \pm 5.89)$ & $12.49( \pm 2.27)$ & 9.57 \\
$\mathbf{5 1 - 6 0}$ & $\mathbf{5 1}$ & & & $( \pm 2.18)$ \\
& & $41.98( \pm 7.43)$ & $11.47( \pm 2.28)$ & 8.39 \\
& & & & $( \pm 2.30)$ \\
\hline
\end{tabular}

Note: ANOVA (F)

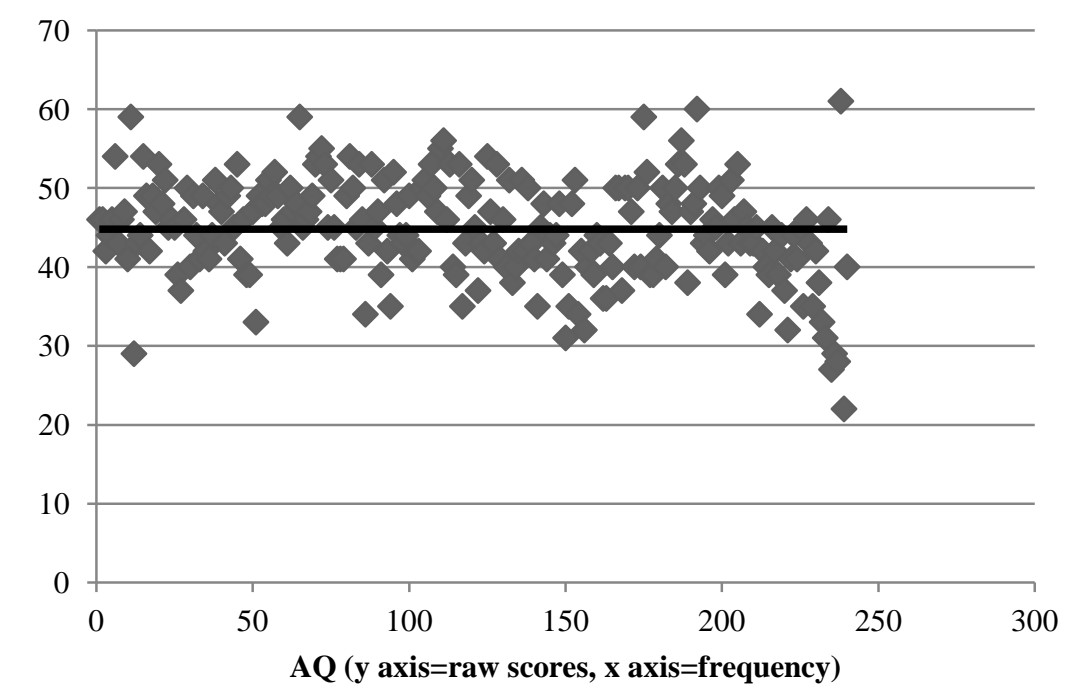

Figure 2: Distribution of test scores on $A Q$ scale 